\title{
Systematic Review of Exocrine Pancreatic Insufficiency after Gastrectomy for Cancer
}

\author{
Jennifer Straatman ${ }^{a} \quad$ Jim Wiegel $^{\mathrm{a}} \quad$ Nicole van der Wielen $^{\mathrm{a}} \quad$ E.P. Jansma ${ }^{\mathrm{b}}$ \\ Miguel A. Cuesta ${ }^{a}$ Donald L. van der Peet ${ }^{a}$

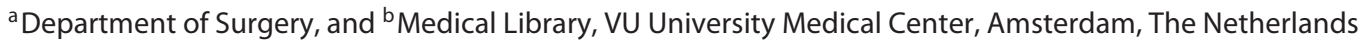

\section{Keywords}

Exocrine pancreatic insufficiency - Gastric cancer .

Gastrectomy

\begin{abstract}
Background: Survival rates after a total gastrectomy with adequate lymphadenectomy are improving, leading to a shift in outcomes of interest from survival to postoperative outcomes and symptoms. In this systematic review, we investigate gastrointestinal symptoms that occur after a gastrectomy in relation to exocrine pancreatic insufficiency and the effect of pancreatic exocrine enzyme supplementation on these symptoms. Methods: Online databases PubMed, Embase, and Cochrane Library were systematically searched in accordance with the PRISMA guidelines. Studies that researched gastrointestinal symptoms, exocrine pancreatic function, and enzyme supplementation were identified and assessed. Results: The search resulted in a total of 1,023 articles after exclusion of duplicates. After performing a thorough assessment, 4 studies were included for systematic review. Exocrine pancreatic insufficiency was investigated by 2 studies; the results showed a significant decrease of total exocrine pancreatic function of up to $76 \%$. The other 2 studies investigated the effect of pancreatic enzyme supplementation and found minor improvement in fecal consistency and a decrease in high-degree steatorrhea. No differences in individual symptom scores were reported. Conclusion: Gastrointestinal symptoms such as steatorrhea, bloating, and dumping syndrome may be related to exocrine pancre-
\end{abstract}

\section{KARGER}

(C) 2017 S. Karger AG, Basel

E-Mail karger@karger.com

www.karger.com/dsu atic function, initiated by total gastrectomy. Treatment with pancreatic enzymes had a minor positive effect on patients. It should be noted that these studies were of a small sample size and low quality. New and larger RCTs are necessary to either prove or disprove the benefit of pancreatic enzyme replacement therapy in the treatment of the gastrointestinal symptoms after total gastrectomy.

(c) 2017 S. Karger AG, Basel

\section{Introduction}

Although survival rates are on the rise among patients with gastric cancer especially after the implementation of neoadjuvant therapy, gastrectomy with adequate lymphadenectomy remains the only curative treatment available $[1,2]$. In up to $90 \%$ of patients following gastrectomy, a wide array of gastro-intestinal symptoms and complications is reported $[3,4]$. A few frequently observed symptoms are diarrhea, steatorrhea, flatulence, loss of appetite, and increased bowel movements, and these symptoms occur most often in combination with each other and may finally result in malnutrition and weight loss $[5,6]$. Although gastric resections have been performed since 1881 , the exact cause of these post-surgical symptoms is still unclear [7].

Several hypotheses have been proposed to explain gastrointestinal symptoms following gastric resection, such as bacterial colonization of the duodenum, low-calorie intake due to changed eating habits, pancreatic insufficiency

Dr. Jennifer Straatman

Department of Surgery, VU University Medical Center

De Boelelaan 1117 ZH 7F020

NL-1081 HV Amsterdam (The Netherlands)

E-Mail je.straatman@vumc.nl 
due to a loss of stimulation of the pancreas, and a rapid upper intestinal transit time $[4,5]$. Frequently observed symptoms such as diarrhea and steatorrhea have all been described in relation to pancreatic insufficiency [8].

Loss of gastric pancreatic innervation and the loss of release of hormones like cholecystokinine are hypothesized to affect the pancreatic function. Whether these theories, solely or in combination, may attribute to a decreased exocrine function of the pancreas is yet to be determined [9].

As stated, many patients suffer from gastrointestinal symptoms. It is unclear how many patients are affected by exocrine pancreatic insufficiency after gastrectomy and whether these patients could benefit from supplementary therapy. We performed a systematic review of the literature to assess the extent of patients who are affected by exocrine pancreatic insufficiency after gastrectomy for cancer and the effects of exocrine pancreatic enzyme supplementation.

\section{Material and Methods}

\section{Literature Search}

In order to identify all relevant publications, a systematic search in the bibliographic databases PubMed, Embase and the Cochrane Library was conducted from inception to November 21, 2015. Search terms included controlled terms from Mesh in PubMed and Emtree in Embase as well as free text terms. Free text terms alone were used in the Cochrane Library. The main outcome measurement was the incidence of gastrointestinal symptoms after enzyme supplementation.

For each database, search terms were included expressing "stomach neoplasms" in combination with terms comprising "surgery" and "pancreatic enzymes/function/insufficiency" along with their synonyms or abbreviations. Full search is displayed in Figure 1. For Embase and PubMed, a fourth selection criteria "publication type" was used. Case reports, interviews, and letters were not included in the search. A systematic review was performed in accordance with the PRISMA guidelines for systematic reviews and meta-analysis; no review protocol was used [10].

\section{Selection Criteria and Definitions}

Two authors assessed the search findings for potential eligibility (J.W. and J.S.) using the articles of the 3 bibliographic databases. The articles were screened for title and abstract, taking into account the predefined inclusion and exclusion criteria. Inclusion criteria comprised (1) stomach cancer, (2) gastrectomy, (3) exocrine pancreatic function, and (4) pancreatic enzyme supplementation. Exclusion criteria included (1) non-English, Dutch, German or Spanish articles, (2) case reports, (3) endocrine pancreatic insufficiency, (4) non-original databases, and (5) pancreatitis. The reference lists of included articles were crosschecked for additional articles of interest. Figure 1 summarizes the search result and selection process in a flowchart.

Review: Pancreatic Insufficiency after Gastrectomy

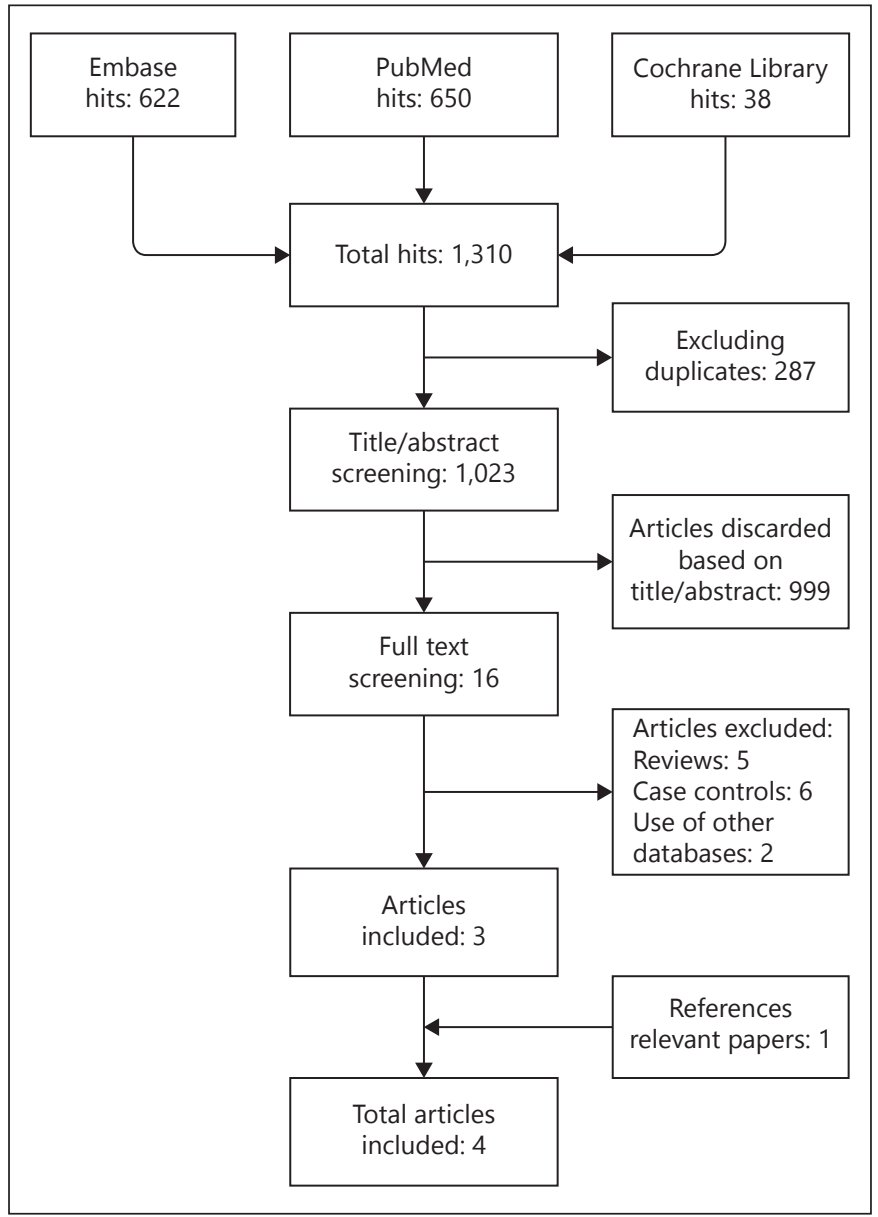

Fig. 1. A flowchart of the article selection.

Quality Assessment

The quality of the identified studies was assessed using the Newcastle-Ottawa assessment scale for observational studies and the Jadad score for randomized controlled clinical trials [11, 12]. The level of evidence was rated by the Centre for Evidence-Based Medicine (CEBM) levels of evidence score [13].

\section{Results}

\section{Data Extraction and Quality Assessment}

A total of 1,310 studies were identified as a result of the search carried out on the PubMed, Embase, and Cochrane databases from the time of inception of this study to August 30,2015 . One thousand twenty-three articles were selected after excluding duplicates. The remaining studies were examined based on their title and abstract. Nine hundred ninety-nine were discarded because they did not match the predefined selection criteria. The full texts of the remaining 16 articles were assessed, after which 3 articles 


\begin{tabular}{|c|c|c|}
\hline Search & Query & Items found \\
\hline$\# 5$ & $\begin{array}{l}\text { Search \#4 NOT ("addresses"[publication type] OR "biography"[publication type] OR "case reports" [publication type] OR } \\
\text { "case report"[ti] OR "comment"[publication type] OR "directory"[publication type] OR "editorial"[publication type] OR } \\
\text { "festschrift"[publication type] OR "interview"[publication type] OR "lectures"[publication type] OR "legal cases" } \\
\text { [publication type] OR "legislation"[publication type] OR "letter"[publication type] OR "news"[publication type] OR } \\
\text { "newspaper article"[publication type] OR "patient education handout"[publication type] OR "popular works" } \\
\text { [publication type] OR "congresses"[publication type] OR "consensus development conference"[publication type] } \\
\text { OR "consensus development conference, nih"[publication type] OR "practice guideline"[publication type]) } \\
\text { NOT (animals[mh] NOT humans[mh]) }\end{array}$ & 650 \\
\hline$\# 4$ & Search \#1 AND \#2 AND \#3 & 678 \\
\hline$\# 3$ & $\begin{array}{l}\text { Search "exocrine pancreatic insufficiency"[Mesh] OR ((pancrea*[tiab] OR pancreas*[ot]) AND (insufficien*[tiab] OR } \\
\text { function*[tiab] OR insufficien*[ot] OR function*[ot])) }\end{array}$ & 41,455 \\
\hline$\# 2$ & $\begin{array}{l}\text { Search "surgical procedures, operative"[Mesh: no exp] OR "anastomosis, surgical"[Mesh] OR "digestive system surgical } \\
\text { procedures"[Mesh] OR "surgical procedures, elective"[Mesh] OR "gastrectomy"[Mesh] OR "surgery"[tiab] OR } \\
\text { "operation"[tiab] OR "resection"[tiab] OR "surgery"[ot] OR "operation"[ot] OR "resection"[ot] }\end{array}$ & $1,603,815$ \\
\hline$\# 1$ & $\begin{array}{l}\text { Search "stomach"[Mesh] OR stomach*[tiab] OR gastric*[tiab] OR cardia[tiab] OR fundus[tiab] OR stomach*[ot] OR } \\
\text { gastric*[ot] OR cardia[ot] OR fundus[ot] }\end{array}$ & 340,467 \\
\hline
\end{tabular}

Fig. 2. Search hits in the online databases PubMed, Embase, and Cochrane.

were identified for this review. An extra article was identified by cross-checking the references of relevant papers. A flowchart for article selection is displayed in Figure 2.

A quality assessment of the included articles was performed using the Newcastle-Ottowa assessment scale for observational studies and the Jadad score for randomized clinical trials $[11,12]$. The quality of the studies varied between levels 2, 3, and 4 on CEBM levels of evidence [13]. No further studies were excluded. Characteristics of the included studies are displayed in Table 1, the quality assessment is depicted in Table 2.

The articles were assessed and results were described based on exocrine pancreatic insufficiency after total gastrectomy and enzyme supplementation after gastrectomy.

\section{Pancreatic Insufficiency}

Exocrine pancreatic insufficiency as a cause for gastrointestinal symptoms post-gastrectomy was examined by 2 studies. Both prospective studies used the decrease in excretion of exocrine pancreatic enzymes such as chymotrypsin, lipase, and bicarbonate as a measure for exocrine pancreatic insufficiency; Gullo et al. [14] compared pancreatic secretion of patients who underwent gastrectomy with controls in contrast to Friess et al. [15] who measured pre- and postoperative pancreatic secretion in gastrectomy patients. Gullo et al. [14] found a mean decrease in bicarbonate, lipase, and chymotrypsin of $47.9,38.7$, and $24.2 \%$ in 12 patients respectively. A stimulation test with secretin and cerulein did not produce any additional increase. Eight out of 12 patients had a measured fecal fat excretion over $7 \mathrm{~g} / 24 \mathrm{~h}$. No significant correlation between fecal fat excretion and lipase excretion was found [14]. The stimulation test with secretin and cerulein resulted in the study of Friess et al. [15] in a mean decrease of $92 \%$ of bicarbonate $(p<$ $0.01), 47 \%$ amylase $(p<0.05)$, and $91 \%$ chymotrypsin $(p<$ $0.01)$ in 15 patients. The total amount of pancreatic secretion was after secretin and cerulein stimulation decreased with $76 \%(p<0.01)$. Gastrectomy did not only influence the pancreatic enzyme output; gastrointestinal hormone blood levels were also altered. Gastrin levels were significantly reduced by $43 \%$, and pancreatic polypeptide (PP) levels were decreased by $61 \%$. Three months later, PP was still reduced by $42 \%$ in comparison to preoperative levels.

\section{Enzyme Supplementation}

Two studies investigated the effects of enzyme supplementation on gastro-intestinal symptoms in patients with exocrine pancreatic insufficiency after total gastrec- 
Table 1. Study characteristics

\begin{tabular}{|c|c|c|c|c|c|c|}
\hline References & Date & Type of research & $\begin{array}{l}\text { Number of } \\
\text { patients }\end{array}$ & $\begin{array}{l}\text { Age, years } \\
\text { mean (range) }\end{array}$ & Men, \% & $\begin{array}{l}\text { Time postoperatively, } \\
\text { median (range) }\end{array}$ \\
\hline \multicolumn{7}{|c|}{ Exocrine pancreatic insufficiency } \\
\hline Gullo et al. [14] & 1979 & Prospective observational & 12 & $42(29-74)$ & 50 & $10(7-76)$ \\
\hline Friess et al. [15] & 1996 & Prospective observational & 15 & $62(-)^{*}$ & 80 & $3(-)$ \\
\hline \multicolumn{7}{|l|}{ Enzyme suppletion } \\
\hline Armbrecht et al. [16] & 1988 & Double blind cross-over & 15 & $64(47-83)$ & 66 & $20(4-156)$ \\
\hline Brägelmann et al. [17] & 1999 & RCT & 52 & $57(50-65)^{*}$ & 73 & $\begin{array}{l}13 \text { (placebo) } \\
4 \text { (intervention) }\end{array}$ \\
\hline
\end{tabular}

Table 2. Quality assessment: Newcastle-Ottawa assessment for observational studies, Jadad score for RCTs

\begin{tabular}{|c|c|c|c|c|c|c|c|c|c|}
\hline References & $\begin{array}{l}\text { Representativeness } \\
\text { exposed cohort }\end{array}$ & $\begin{array}{l}\text { Selection non } \\
\text { exposed cohort }\end{array}$ & $\begin{array}{l}\text { Ascertainment } \\
\text { of exposure }\end{array}$ & $\begin{array}{l}\text { Outcome of } \\
\text { interest not } \\
\text { present at } \\
\text { start? }\end{array}$ & $\begin{array}{l}\text { Adjusted for } \\
\text { confounders }\end{array}$ & $\begin{array}{l}\text { Reliable } \\
\text { outcome } \\
\text { assessment }\end{array}$ & $\begin{array}{l}\text { Adequate } \\
\text { long-term } \\
\text { follow-up? }\end{array}$ & $\begin{array}{l}\text { Adequately } \\
\text { dealt with loss } \\
\text { of follow-up? }\end{array}$ & $\begin{array}{l}\text { Level of } \\
\text { evidence }\end{array}$ \\
\hline \multicolumn{10}{|l|}{ Newcastle-Ottawa } \\
\hline Gullo et al. [14] & 1 & 0 & 1 & 1 & 1 & 1 & 1 & 1 & 4 \\
\hline Friess et al. [15] & 1 & 0 & 1 & 1 & 0 & 1 & 1 & 1 & 3 \\
\hline \multirow[t]{2}{*}{ Armbrecht et al. [16] } & 1 & 1 & 1 & 1 & 0 & 1 & 1 & 1 & 3 \\
\hline & $\begin{array}{l}\text { Mentioned } \\
\text { randomization }\end{array}$ & $\begin{array}{l}\text { Appropriate } \\
\text { randomization }\end{array}$ & $\begin{array}{l}\text { Mentioned } \\
\text { blinding }\end{array}$ & $\begin{array}{l}\text { Appropriate } \\
\text { blinding }\end{array}$ & $\begin{array}{l}\text { Account all } \\
\text { patients }\end{array}$ & & & & \\
\hline \multicolumn{10}{|l|}{ Jadad score for RCT } \\
\hline Brägelmann et al. [17] & 1 & 0 & 1 & 1 & 1 & & & & 2 \\
\hline
\end{tabular}

tomy $[16,17]:$ one randomized controlled trial and one crossover trial.

Armbrecht et al. [16] performed the double blind crossover study with 15 patients in which every patient underwent a 7 days intervention period, followed or after a 7 days long placebo period. It was found that the stool consistency improved significantly in patients after total gastrectomy $(p<0.05)$. Also, the median fecal fat excretion in patients with high-degree steatorrhea reduced significantly from 643 to $501 \mathrm{mmol} / 72 \mathrm{~h}(p<0.05)$. The degree of steatorrhea of the total group did not significantly decline after Kreon substitution. The 5 symptoms - bloating, nausea, vomiting, dumping and pain - did not change in a significant manner.

Brägelmann et al. [17] performed a prospective parallel, randomized, placebo-controlled, double blind trial on pancreatic enzyme supplementation after total gastrectomy on 52 patients. Although the symptoms - dyspepsia, bloating, early satiety, reflux, and postprandial vomit- ing - did not differ in the enzyme-treated group in comparison with the placebo group, the patients who had had the pancreas enzyme supplementation reported a significant improvement in the quality of life $(p=0.006)$. Fifteen out of 23 treated patients experienced an improvement of symptoms, while only 6 out of 24 placebo-treated patients experienced an improvement. Brägelmann et al. [17] did not find any significant decrease in the median fecal fat output in the enzyme-treated patients $(p=0.1)$.

\section{Discussion}

Gastrointestinal symptoms are reported in up to $90 \%$ of patients following gastrectomy for cancer. The exocrine pancreatic function can be impaired in these patients. Supplementation of pancreatic enzymes showed minor improvements in low-quality studies. 
Table 3. Outcome intervention studies

\begin{tabular}{|c|c|c|c|c|c|c|c|c|}
\hline & Intervention & Intervention & Total & Duration & $\begin{array}{l}\text { Stool } \\
\text { consistency }\end{array}$ & $\begin{array}{l}\text { Bowel } \\
\text { movements }\end{array}$ & $\begin{array}{l}\text { Abdominal } \\
\text { symptoms }\end{array}$ & $\begin{array}{l}\text { Faecal fat } \\
\text { excretion }\end{array}$ \\
\hline $\begin{array}{l}\text { Armbrecht } \\
\text { et al. [16] }\end{array}$ & $\begin{array}{l}\text { Lipase: } 10,000 \text { FIP } \\
\text { amylase: } 10,000 \text { FIP } \\
\text { protease } 650 \text { FIP }\end{array}$ & 12 capsules & $\begin{array}{l}\text { Lipase: } 120,000 \text { FIP } \\
\text { amylase: } 120,000 \text { FIP } \\
\text { protease } 7,800 \text { FIP }\end{array}$ & $\begin{array}{l}\text { 7/7 placebo/ } \\
\text { Creon }\end{array}$ & + & $+/-$ & $+/-$ & $\begin{array}{l}\text { Overall: } \\
+/->350 \\
\text { mmol: }+\end{array}$ \\
\hline $\begin{array}{l}\text { Brägelmann } \\
\text { et al. [17] }\end{array}$ & $\begin{array}{l}\text { Lipase: } 36,000 \text { FIP } \\
\text { amylase: } 27,000 \text { FIP } \\
\text { protease: } 2,400 \text { FIP }\end{array}$ & 9 sachets & $\begin{array}{l}\text { Lipase: } 324,000 \text { FIP } \\
\text { amylase: } 243,000 \text { FIP } \\
\text { protease: } 21,600 \text { FIP }\end{array}$ & 14 days Creon & $+/-$ & $+1-$ & $+/-^{*}$ & $+/-$ \\
\hline
\end{tabular}

$+=$ improvement; $+/-=$ no change; $-=$ worsened; FIP, federation international pharmaceutique. ${ }^{*}$ Abdominal symptoms did not differ in control and intervention group, but the intervention group had a significant improvement in the overall well-being.

A majority of patients reported after total gastrectomy one or more symptoms, such as steatorrhea, reflux, dysphagia, and early satiety, in combination with a lowered overall well-being score $[3,4]$. The exact etiology of these symptoms is unclear. Literature reports different potential causes, of which small intestinal bacterial overgrowth, rapid oro-cecal transit time, and exocrine pancreatic insufficiency are the most commonly reported [18-20]. This review examined whether pancreatic insufficiency is present after total gastrectomy, and as an extension to this, whether exocrine pancreatic insufficiency could be responsible for gastrointestinal symptoms reported after gastrectomy, and whether this necessitates the prescription of supplementation of pancreatic enzymes.

The exocrine pancreatic output differs greatly interindividually; EPI is therefore mainly a clinical diagnosis and the treatment is based on clinical symptoms such as diarrhea, steatorrhea, weight loss, and flatulence [3].

Exocrine pancreatic enzymes were significantly decreased following total gastrectomy in comparison to preoperative outcomes $[14,15]$. Friess et al. [15] only used direct testing methods for assessing exocrine pancreatic insufficiency. The gold standard for indirect testing is the 72-h fecal fat collection, expressed as the coefficient of fat absorption $[8,21]$. Ideally, both measurements are performed in the assessment of exocrine pancreatic function to possibly correlate the amount of dysfunction of the pancreas to the effect of enzyme supplementation. Gullo et al. [14] performed the 72-h fecal fat collection and did find that out of 8 patients with fecal fat excretion per $24 \mathrm{~h}$, 6 had reduced lipase output, but with numbers as small as this, it is difficult to interpret these results. Comparing the 2 studies is difficult because of the variation in their study design. Gullo et al. [14] compared the pancreatic function between healthy controls and patients post-surgery, while Friess et al. [15] compared the function pre- and post- surgery, which may alter the level of decrease in the pancreatic function because of the possible inter-individual difference in pancreatic baseline function. Studies describe that impaired fat digestion occurs only when the pancreatic output is less than $10 \%$ of the normal output. Whether the measured decrease in pancreatic function of $76 \%$ found by Friess et al. [15] is sufficient to cause gastrointestinal symptoms is therefore debatable [22].

Recent RCTs supported the supplementation of pancreatic enzymes in patients with exocrine pancreatic insufficiency due to chronic pancreatitis or pancreatic surgery $[23,24]$. Based on these findings, the findings of decreased pancreatic function after total gastrectomy supplementation with pancreatic enzymes to help relieving of the symptoms is on trial. When assessing the results thoroughly, the studies only reported minor improvements as shown in Table 3. The individual symptom scores did not significantly change and the fecal fat excretion did not change overall. Brägelmann et al. [17] found an improvement in the overall well-being, whereas no differences in individual symptom scores were observed. It should be noted that both studies used very different dosages, with one study only substituting one third of the proposed necessary levels $[16,24]$. Whether this is sufficient enough to reach functional levels is unclear; the minimum doses of lipase that are considered are in the range of 25,000-50,000 units of lipase/meal [25]. Neither of the 2 studies reported the correlation between exocrine pancreatic function and gastrointestinal symptoms. Although previous studies suggested that the secretion of pancreatic enzymes are reduced following gastrectomy, it has not been established whether all of the patients included in these 2 studies suffered from decreased pancreatic output.

The results of improved overall well-being, without differences in the symptom scores, may be explained by
368

Dig Surg 2017;34:364-370

DOI: $10.1159 / 000454958$
Straatman/Wiegel/van der Wielen/ Jansma/Cuesta/van der Peet 
the small sample size, thus masking the differences in subscores. The rapid oral-cecal transit time, which inhibits the proper mixing of food and pancreatic enzymes, could also play a role [4].

The quality of the included studies was assessed using the Jadad score and Newcastle-Ottawa scale for observational studies, as displayed in Table 2. In addition, the Bias Detection Tool from the Cochrane group was used to identify the different sorts of biases that existed. Selection bias could easily be present in the studies investigating pancreatic insufficiency because of the lack of a proper description of patient selection $[14,15]$. Performance and detection bias are most likely little or completely absent in the 2 studies investigating the supplementation of pancreatic enzymes because the study design included the double-blinding of both the patients and the researchers [16, 17]. There was no evidence that attrition or reporting bias could influence the results in all 4 of the included studies.

An important limitation of this review is the lack of high-level evidence studies. A meta-analysis was not deemed appropriate since the studies were found to be heterogeneous. The reported studies were small and underpowered with only one randomized study. The median time between surgery and measurement of exocrine pancreatic function varied widely between studies, possibly altering the symptoms and quality of life scores [26]. Surgical techniques and fast-track care have improved patient outcomes over time $[1,27]$. Taking all this information into account, the results found in these studies should be carefully interpreted. New, large prospective studies are necessary to investigate the correlation between the decrease in exocrine pancreatic output and pancreatic insufficiency, and to what extent the supplementation of pancreatic enzymes helps in the improvement of the quality of life after total gastrectomy.

\section{Conclusion}

Exocrine pancreatic function is impaired after total gastrectomy. Pancreatic enzyme supplementation has been applied pragmatically, with minor improvements reported in small, heterogeneous studies. Future research should aim to assess the extent of exocrine pancreatic insufficiency after total gastrectomy, the relation with gastro-intestinal symptoms, and the indication for enzyme supplementation. Large-scale RCTs are necessary to investigate the potential future role of pancreatic enzyme supplementation in the effort of finding relief from gastrointestinal symptoms.

\section{Disclosure Statement}

Drs. J. Straatman, J. Wiegel, Drs. N. van der Wielen, E.P. Jansma, Prof. Dr. M.A. Cuesta, and Prof. Dr. D.L. van der Peet report no medical financial interests, sponsorship, funding arrangements, or potential conflicts of interest, direct or indirect, relating to this research or the subject of this paper.

\section{References}

1 Cunningham D, et al: Perioperative chemotherapy versus surgery alone for resectable gastroesophageal cancer. N Engl J Med 2006; 355:11-20.

2 GASTRIC (Global Advanced/Adjuvant Stomach Tumor Research International Collaboration) Group, Paoletti X: Benefit of adjuvant chemotherapy for resectable gastric cancer: a meta-analysis. JAMA 2010;303: 1729-1737.

3 Brägelmann R, et al: Nutrient malassimilation following total gastrectomy. Scand J Gastroenterol Suppl 1996;218:26-33.

4 Armbrecht U, et al: Causes of malabsorption after total gastrectomy with Roux-en-Y reconstruction. Acta Chir Scand 1987;154:37-41.

5 Friess $\mathrm{H}$, et al: Indication for pancreatic enzyme substitution following gastric resection. Pancreatology 2001;1(suppl 1):41-48.

6 Bradley EL 3rd, et al: Nutritional consequences of total gastrectomy. Ann Surg 1975;182: 415-429.

Review: Pancreatic Insufficiency after Gastrectomy
7 Morton L: Medical Bibliography, 1954.

8 Domínguez-Muñoz JE: Pancreatic exocrine insufficiency: diagnosis and treatment. J Gastroenterol Hepatol 2011;26(suppl 2):12-16.

9 Domínguez-Muñoz JE: Pancreatic enzyme replacement therapy: exocrine pancreatic insufficiency after gastrointestinal surgery. HPB (Oxford) 2009;11(suppl 3):3-6.

10 Liberati A, et al: The PRISMA statement for reporting systematic reviews and meta-analyses of studies that evaluate health care interventions: explanation and elaboration. PLoS Med 2009;6:e1000100.

11 Wells GA, et al: Newcastle-Ottowa Quality assessment scale. http://www.ohri.ca/programs/clinical_epidemiology/oxford.asp.

12 Jadad AR, et al: Assessing the quality of reports of randomized clinical trials: is blinding necessary? Control Clin Trials 1996;17:1-12.

13 OCEBM Levels of Evidence Working Group: The Oxford 2011 levels of evidence. 2011. http://www.cebm.net/index.aspx?o=5653.
14 Gullo L, Costa PL, Ventrucci M, Mattioli S, Viti G, Labò G: Exocrine pancreatic function after total gastrectomy. Scand J Gastroenterol 1979;14:401-407.

15 Friess $\mathrm{H}$, et al: Maldigestion after total gastrectomy is associated with pancreatic insufficiency. Am J Gastroenterol 1996;91:341-347.

16 Armbrecht U, Lundell L, Stockbruegger RW: The benefit of pancreatic enzyme substitution after total gastrectomy. Aliment Pharmacol Ther 1988;2:493-500.

17 Brägelmann R, et al: The effect of pancreatic enzyme supplementation in patients with steatorrhoea after total gastrectomy. Eur J Gastroenterol Hepatol 1999;11:231-237.

18 Paik CN, et al: The role of small intestinal bacterial overgrowth in postgastrectomy patients. Neurogastroenterol Motil 2011;23: e191-e196.

19 Bae JM, et al: Nutritional status of gastric cancer patients after total gastrectomy. World J Surg 1998;22:254-260; discussion 260-261. 
20 Brägelmann R, et al: Small bowel bacterial overgrowth in patients after total gastrectomy. Eur J Clin Invest 1997;27:409-416.

21 Van De Kamer JH, Ten Bokkel Huinink H, Weyers HA: Rapid method for the determination of fat in feces. J Biol Chem 1949;177:347355.

22 DiMagno EP, Go VL, Summerskill WH: Relations between pancreatic enzyme outputs and malabsorption in severe pancreatic insufficiency. N Engl J Med 1973;288:813-815.
23 Safdi M, et al: The effects of oral pancreatic enzymes (Creon 10 capsule) on steatorrhea: a multicenter, placebo-controlled, parallel group trial in subjects with chronic pancreatitis. Pancreas 2006;33:156-162.

24 Whitcomb DC, et al: Pancrelipase delayedrelease capsules (CREON) for exocrine pancreatic insufficiency due to chronic pancreatitis or pancreatic surgery: a double-blind randomized trial. Am J Gastroenterol 2010;105: 2276-2286.

25 Friess H, Michalski CW: Diagnosing exocrine pancreatic insufficiency after surgery: when and which patients to treat. HPB (Oxford) 2009;11(suppl 3):7-10.
26 Shan B, et al: Systematic review on quality of life outcomes after gastrectomy for gastric carcinoma. J Gastrointest Oncol 2015;6:544560.

27 Straatman J, et al: Minimally invasive versus open total gastrectomy for gastric cancer: a systematic review and meta-analysis of short-term outcomes and completeness of resection: surgical techniques in gastric cancer. World J Surg 2016;40:148157. 